\title{
How do We Remember Traumatic Events such as Massacre Through Architecture?
}

\author{
Na Liu* \\ Hezhou University, Hezhou 542899, Guangxi Zhuang Autonomous Region, China \\ *Corresponding author: Na Liu, liuna95116@126.com
}

\begin{abstract}
Architecture is becoming an extraordinary method to save memories. This paper aims to show the relationship between traumatic events and architecture. This paper indicates that the positive side of memorial architecture from traumatic incidents on strengthening national identity, cultivate patriotism in the educational field, and becoming the city's icon. It also presents the building architecture drawbacks on emotion and mentality of people and occupies much city's area. Indeed, giving depth research on typical cases to analyse the influence for people. The findings clearly show that building is common use in remembering traumatic events.
\end{abstract}

Keywords: Traumatic events; Architecture; Memory

Publication date: September 2021; Online publication: September 30, 2021

\section{Introduction}

Since 1946, making genocide a crime by International Law, mourning of the dead, and advocacy of antiwar are becoming essential themes of social activity. In recent years, a large number of memorial museums have been built to commemorate historical events around the world. Architectures are used to describe and spread the process of history as a medium ${ }^{[12]}$. Through architectural language, humanity acquires more historical information. Moreover, Warwick reports that architecture is more real than the picture and text of the history book. It leads to generate the number of critical historical events memorials.

After two world wars, human society made profound introspection, and massacre memorial architecture plays a vital role as people believe that it is a useful model for remembering victims and events. Many countries of Europe have built the Jewish Holocaust memorial, such as Germany, America, and Israel. In China, the government established a memorial hall in Nanjing to commemorate the massacre in 1982 ${ }^{[19]}$. In general, a large percentage of people (about $60 \%$ to $90 \%$ ) would encounter traumatic incidents in natural life ${ }^{[7]}$. However, to resist the missing time, people preserve unchangeable memories, and emotions via architecture.

\section{The relationship between traumatic events and architecture}

Establishing memorial as a form of architecture is affecting traumatic memories. Sternberg ${ }^{\text {[2] }}$ defines 'memory' as a procedure that portrays past episodes to use experiences at present. In 1990, 'traumatic' was first used to describe Holocaust memories ${ }^{[2]}$. Many people who suffered from the holocaust is the main reason for creating traumatic memory. Similarly, the Chinese massacre is also a traumatic memory. In 1982, the Chinese government built the Memorial Hall of the Victims in Nanjing Massacre by Japanese Invaders and some monuments to react to traumatic events as the Japanese erased the historical atrocities for China as much as possible on the textbook of high school.

After the memorial was established, ultimately, the memorial became a channel of memory connected 
to the citizens of Nanjing with history and reality, and it became an extraordinary place to commemorate and commemorate the victims and compatriots. The traumatic event leads to pain and lousy memory like a tragedy. While people who have experienced shocking incident is unwilling to mention those distressing memories, the future generations should not forget the past. Memorial consists of mnemonic fragments that embody the development of history. Architecture aims to become a bridge to narrow the generational gap and promote generational connection ${ }^{[2]}$.

\section{It is helpful to remember the traumatic events through architecture}

Through architecture to remember the traumatic event, which brings benefits such as strengthening national identity, promoting the spiritual and cultural-historical learning of young generations and being an icon of the city.

This paragraph will demonstrate how to strengthen national identity in architecture establishment. The national identity not only was a crucial part of the building environment but also society and humanity are support and served by architecture. In this way, national identity has strengthened.

Memorial architecture has increased the importance of education, which memorial is a kind of architecture ${ }^{[4]}$. Architecture and education are close to connecting; the Memorial is a type of architecture that is a centre of learning in some fields such as colonialism, power and nationalism like the Holocaust Museum and Memorial Hall in Nanjing ${ }^{[15]}$. According to collective memories, the local government uses architectural language to express a historical event in enhancing the awareness of patriotism. The amount of historical material has been arranged in the memorial. Indeed, Barry ${ }^{[1]}$ reported that architecture use is a popular method for presenting memories and the awareness of patriotism or nationalism in the world. For instance, many schools or universities would like to organise a visit for memorials or monuments. The explanations and historical recollections allow college students to deeply understand the past, present, and future of the nation, to preserve and inherit the collective memory of the nation, to fully appreciate the suffering and creative glory suffered by the nation, and to stimulate future generation's sense of lofty mission to rejuvenate the country. As a showcase for ethnic trauma, the memorial has the function of popularising patriotic education. Many parents would visit it with their little children. Liu ${ }^{[14]}$ noted that building a memorial encourages teenagers to invigorate the national spirit and warn compatriots to avoid the recurrence of historical tragedies. In the lecture of the memorial, let the teenagers seriously reflect on their deficiencies, reflect on their personality defects, and learn from the older generation's outstanding personality to correct their personality defects. Also, by setting up a commemorative event and anniversaries to evoke the awareness of national emotion. It is an excellent way that the youth generation has to collaborate with the memorial in the learning of history.

These building can be an icon. Iconic buildings commonly have the most recognisable in a city. They belong to the special regionally cultural symbol; even it represents the city's image. Some people associate the Memorial Hall of China with Nanjing and Nanjing traumatic events. For instance, Zhengzhou Erqi memorial was built in 1971 to commemorate the martyrs who died during the Jing-han railway strike ${ }^{[16]}$. Those citizens who live in Zhengzhou know this historical episode by looking at that building. As a result, architecture becomes an iconic building not only is vital for the city, but the iconic building also carries everything in the city, such as culture and spirit. After that, the memorial is also a window that is used to peaceful communicate. For example, the Memorial Hall of the Victims in Nanjing Massacre by Japanese Invaders for more than 20 years, the memorial accommodates friends from more than 50 countries, of which Japan is the majority. The Japanese here held a mourning ceremony with guilt and a heavy heart. Express your feelings and express your feelings of remorse and reflection. In the building era, it creates a unique national architecture via architectural style ${ }^{[10]}$. Let people associate architecture with a city or state. 


\section{The Memorial Hall of the Victims in Nanjing Massacre by Japanese Invaders}

\subsection{Phase I}

The Massacre Memorial carries a substantial history, so its expression is calm but powerful ${ }^{[6]}$. In 1985 , the Nanjing government had to build a memorial for victims of Japanese invaders. The Phase I memorial was designed by Qi Kang of the school of Architecture of Southeast University. It is one of the top ten of architectural designs in China.

The entire building is made of grey and white marble, with a magnificent and solemn solemnity. The main building of the memorial hall consists of a mourning square, cobblestone square, sculpture wall, historical heritage site, the wall of the list of the dead, sculpture square and exhibition halls ${ }^{[18]}$.

The tapered building is easy to distinguish from other buildings. The building facade becomes a triangular shape. It is a unique design within surrounding buildings. Furthermore, the building is modern architecture to integrate with the surrounding structures. The terrain is one of the critical factors for architectural structure and shape considerations ${ }^{[18]}$. On both sides of the building are the main streets of the city. The overall shape is like a "boat of peace." Due to the terrain of the intersection, the building is located at the angle of the two roads and has a limited available architectural area ${ }^{[18]}$. Part of the architect's theme is placed in the underground space, and the whole building resembles a triangle inserted diagonally into the ground. This formed a large-scale sloped roof that was used as a memorial square.

Pebble is the primary material in the pavement in the landscape. The use of pebble is to express Japanese guilty like the bones of the dead. Large area uses in pebbles as walking sound like earth's cry, let people get the theme of death and life ${ }^{[5]}$.

In the internal area, the broken shape can better fit the space. Meanwhile, it means that most families

had broken in the war. Because of the irregular building, the ceiling needs to present different shapes ${ }^{[18]}$. Additionally, the sloping wall enhances the shaping of space atmosphere and emotion. The inward tilt of the single interface can create a feeling of intimacy and even oppression, and the outward tilt creates an open atmosphere.

Materials are elements that can express the attitude of the building. Choosing the right materials and colours will play an essential role in improving the building's shape and strengthening architectural ideology ${ }^{[18]}$. The building was established in the use of grey-white marble, which is magnificent and solemn. These materials can guarantee monumentality. The facade is made of dry hanging stripe-shaped stone, which is cold and rough, and the carved texture seems to be a scar, symbolizing the cruelty of this tragedy (Ibid).

Water can carry and convey memorial emotions through static reflections and dynamic surges. The pool in the Massacre memorial site can reflect the sky, buildings and sculptures, deepening the sense of outer space. The water is designed at the entrance of the Nanjing Massacre Memorial Hall, reflecting the sculpture group. Behind the bones showroom 'Soul of Comfort' was created on the pebble wilderness, with the dead trees in the distance as its background; The long pool of Peace Park is a classic in the construction of still water ${ }^{[24]}$. The extension of the pool guides people's eyes to look forward to the distance, creating an empty and quiet space artistic conception, and expressing people's sorrow for the dead.

\subsection{How does memorial spaces affect the visitors?}

Architecture has a considerable impact on the mental field and emotions. Although history is inevitable as a part of memory, building memorials as a marker would lead to being stress to face shameful past ${ }^{[21]}$. Often, people release their emotions via architecture with the memorial. Traumatic feeling means that people face tremendous destruction, and the disappearance of disasters and lives is a manifestation of their inability to deal with the accident and the loss of their grief. Traumatic emotion is universal in memorial space, and they are an essential component of emotions in the memorial area. The architecture was a space 
for residents to live and visit or display; Geographers ${ }^{[11]}$ state that the formation of architectural form is vital for people in architectural space.

Even though emotion creation a vital role in building memorials, it leads to some adverse problems. Emotion refers to a feeling that generates a mental response through the stimulation of external factors. A Memorial is a place where it accumulates all historical memories and experiences to commemorate people and events for future generations. As the purpose of the memorial is to provide appreciation beyond representation, and this mode is focusing on elements, sounds, and light to make people feel real historical development ${ }^{[24]}$.

Likewise, asserts that memorial displays memorable events and persons who are the hero or doing extraordinary things as a narrator. Once visitors come into the memorial, although the memorial is not an emotional manager, their emotions change according to the atmosphere created in the space. But some memorials, the scenes in the memorial are too real so that some visitors get the feeling of fear and tension.

\section{5. the Memorial Hall of the Victims in Nanjing Massacre by Japanese Invaders \\ 5.1. Phase III}

Phase III has significant differences from Phase I. Phase III building intend to embody the emotion of victory and a happy ending ${ }^{[9]}$. Phase I building narrated a whole historical traumatic event as a vital memory in Nanjing. However, Phase III building is different from the aim of expansion to express various emotional atmospheres and continue the city's memory ${ }^{[9]}$.

Interior colour is the main difference between Phase I and Phase III. Colour is the dominant element of the building. Analysis of the Massacre Memorial Hall colour processing is the most direct way to study its emotional expression ${ }^{[20]}$. Different colour constructions have different emotional connotations and diverse functions and different personalities. Grey is the key colour in the façade of Phase III and Phase III. Phase III uses concrete in the façade that is a commonly used material in monumental buildings. The concrete material conforms to the straightforward, solemn and elegant temperament of the Massacre Memorial Museum, which can accurately convey the architectural emotions and make the visitors have the same sense ${ }^{[20]}$.

Interior space has used many curved lines on the wall design. Phase I gives the feeling of trauma, but phase III shows a more relaxed atmosphere ${ }^{[9]}$.

By contrast, phase I uses black and grey as the primary colour. There are no other bright colours, and the main exhibition hall is rarely illuminated. Facilities that maintain is natural darkness. It means the darkness of human nature, the darkness of history, the darkness of hope, all of the darkness is summarised in the exhibition design of the memorial hall, silently telling that period of pain, depression, and anger.

\section{Conclusion}

The traumatic event is remembering through architecture. Architecture is universal to use to remember traumatic memories as it is permanent. This paper has illustrated that architecture has some negative sides on retaining traumatic, while it would generate more benefits. In this study, we sought to search for the relationship between trauma and architecture. Architecture seems to be a bridge, which future generations can access traumatic historical memories. Architecture use is useful in remembering traumatic memories is that states can strengthen national identity, becoming the city's icon, and youth generation can cultivate patriotism in the educational area. In sum, people remember traumatic event such as a massacre can use architecture associated with diverse architectural factors.

\section{Disclosure statement}

The author declares no conflict of interest. 


\section{References}

[1] Barry K, 2017, Buildings as Artifacts: Heritage, Patriotism, and the Constructed Landscape, 5(1): 3. Available at: http://doi.org/10.5334/ah.189.

[2] Bathrick D, Prager B, Richardson MD, 2008, Visualizing the Holocaust: Documents, Aesthetics, Memory. Rochester, Camden House, New York.

[3] Bennett T, 1995, The Birth of the Museum. History, Theory, Politics. London, Routledge.

[4] Cuny FC, 1999, Fred C. Cuny Memorial Continuing Education Series Principles of Disaster Management Lesson 5: Program Supervision, Monitoring, and Control. Prehospital and Disaster Medicine, 14(3): 91-103.

[5] Dong WR, 2016, Space Organization Model of Memorial Buildings for Major Events: A Case Study of the Nanjing Massacre Memorial Hall. Doors \& Windows, 11.

[6] Feldman A, 2004, Memory Theatres, Virtual Witnessing, and the Trauma-Aesthetic, Biography, 27: 1165.

[7] Fetzner MG, et al., 2011, What is the Association between Traumatic Life Events and Alcohol Abuse/Dependence in People With and Without PTSD? Findings from a Nationally Representative Sample. Depression and Anxiety, 28(8): 632-638.

[8] Guth CME, 1996, Japan 1868-1945: Art, Architecture, and National Identity. Art Journal, 55(3): 16.

[9] He JT, Ni Y, Liu YB, 2015. Expansion of Memorial Hall for the Victims of the Nanjing Massacre by Japanese Invaders. Urban Environmental Design, 10: 62-67.

[10] Jones PR, 2003, National Identity and Architecture.

[11] Kraftl P, Adey P, 2008, Architecture/Affect/Inhabitation: Geographies of Being-In Buildings, Annals of the Association of American Geographers, 98(1): 213-231.

[12] Lazarova J, 2017, Making Symbolic Architecture Matte.

[13] Lemkin R, 1947, Genocide as a Crime under International Law. American Journal of International Law, 41(1): 145-151.

[14] Liu LW, 2016, New West. On the Social Education Responsibility of the Memorial to the Youth, 36.

[15] Nathaniel P, 2019, Does the History of Museum Education Begin?, Journal of Museum Education, 44(4): 337-341.

[16] Niu LZ, 2013, Landmark Building as a Medium., 8: 131-132.

[17] Pavlakoviæ V, Perak B, 2017, The Twentieth Century in European Memory: Transcultural Mediation and Reception. Boston: Brill Press.

[18] Qi K, 1986, The Key to Conception: Remember the Creation of the Nanjing Holocaust Memorial Plan. New Architecture, 2.

[19] Qi K, 1999, The Memorial Hall of the Victims in Nanjing Massacre by Japanese Invaders. Liaoning: Liaoning Science and Technology Press.

[20] Sabine M, 2006, Visualizing Memories: The Hector Pieterson Memorial in Soweto, Visual Anthropology, 19(2): 145-169. Available at: 10.1080/08949460600598695.

[21] Souto A, 2011, Archiving Berlin's Past and Renewing the Ruhr Valley. Austausch.

[22] Sternberg RJ, 1999. Stages of Memory.

[23] Vale LJ, 1992, Architecture, Power and National Identity. London, Yale University.

[24] Waterton E, Dittmer J, 2014, The Museum as Assemblage: Bringing Forth Affect at the Australian War Memorial, Museum Management and Curatorship, 29(2): 122-139.

[25] Xie F, 2018, Analysis of the Public Space Sculpture Layout of the Nanjing Massacre Memorial Hall. Shanxi Architecture., 44(5): 12. 